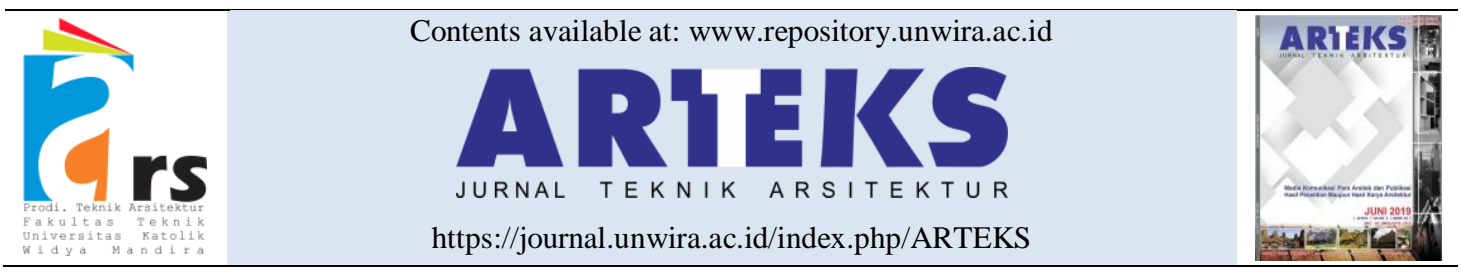

Research paper

doi: $10.30822 /$ arteks.v5i2.448

\title{
Penerapan prinsip desain arsitektur biofilik pada Riau Mitigation and Disaster Management Center
}

\author{
Miftahul Karima, Yohannes Firzal ${ }^{(\mathbb{D})}$, Gun Faisal*iD \\ Jurusan Arsitektur, Fakultas Teknik, Universitas Riau \\ Kampus Binawidya, Jl. HR. Soebrantas KM. 12,5 Pekanbaru, Indonesia
}

\begin{tabular}{|c|c|}
\hline ARTICLE INFO & ABSTRACT \\
\hline $\begin{array}{l}\text { Article history: } \\
\text { Received April 03, } 2020 \\
\text { Received in revised form April 11, } 2020 \\
\text { Accepted May 18, } 2020 \\
\text { Available online August } 01,2020\end{array}$ & $\begin{array}{l}\text { The application of biophilic architecture design principle on Riau } \\
\text { Mitigation and Disaster Management Center } \\
\text { Disaster is a series of events that cause significant loss, even } \\
\text { casualties. Indonesia, which was called as Laboratory of Disaster } \\
\text { was characterized by the increase of complexity and number of }\end{array}$ \\
\hline $\begin{array}{l}\text { *Corresponding author: Gun Faisal } \\
\text { Jurusan Arsitektur, Fakultas Teknik, } \\
\text { Universitas Riau, Indonesia } \\
\text { Email: gunfaisal@gmail.com } \\
\text { ORCID: https://orcid.org/0000-0002-6580- } \\
1701\end{array}$ & $\begin{array}{l}\text { disasters each year, which make mitigation and disaster } \\
\text { management skill should be a top priority. Hence, a facility where } \\
\text { education for mitigation could be held as needed. This facility was } \\
\text { designed for education, recreation, and last evacuation shelter, } \\
\text { located in Pekanbaru, Riau, due there wasn't this type of facility in } \\
\text { the province. Considering its function, biophilic design was chosen } \\
\text { due to its principle of respecting nature; hence users' productivity, } \\
\text { physical and mental health increase and the existence of natural } \\
\text { elements could give comfort and refuge. The design methodology } \\
\text { was a site survey and data collection about Biophilic architecture } \\
\text { design principles and mitigation and disaster prevention center from } \\
\text { journals. The result of this methodology is a design of Mitigation } \\
\text { and Disaster Management Center in Riau. }\end{array}$ \\
\hline
\end{tabular}

\section{Pendahuluan}

Data Informasi Bencana Indonesia (DIBI) tahun 2013 menyebut Indonesia sebagai Laboratory of Disasters karena intensitas bencana yang terjadi semakin kompleks dan meningkat secara signifikan (Wibowo, Surbakti, and Yunus 2013). Posisinya yang berada di jalur cincin api (ring of fire) berkontribusi pada sebagian besar gempa yang terjadi (Madona and Irmansyah 2013). Intensitas hujan yang tinggi di Indonesia juga menyebabkan banjir dan longsor (Yulaelawati 2008). Musim kemarau yang berkepanjangan menyebabkan kebakaran hutan dan asap terutama pada daerah-daerah yang rentan terjadinya kebakaran (Kusmajaya et al. 2019).

Dalam konteks Provinsi Riau, meskipun letaknya tidak berada di wilayah patahan dan zonasi rawan gempa, terdapat 4 sungai besar sehingga, rawan banjir. Bencana lain yang terjadi adalah kebakaran hutan dan lahan hampir tiap tahunnya dikarenakan jumlah titik panas yang banyak. Semua pihak harus terlibat dalam pengendalian Kebakaran Hutan dan Lahan (KARHUTLA), baik itu penanganan ketika kebakaran terjadi, pencegahan dampak kebakaran pada kesehatan, memberikan edukasi kepada anak-anak, memberikan bantuan pencegahan dan bantuan teknologi, dan lain-lain (Pemerintah Pusat 2015).

Bencana semakin banyak terjadi. Namun, penanganan yang lambat, tidak terpadu, dan banyak masyarakat yang kurang memiliki kesadaran akan pentingnya pengetahuan dan kemampuan untuk menyelamatkan diri membuat pengurangan resiko bencana tidak berjalan efektif 
(Juandi 2015). Pengetahuan dan kemampuan mitigasi harus dijadikan prioritas, namun masih banyak masyarakat yang belum menguasai teknik perlindungan diri, bahkan Indonesia belum memiliki standar mitigasi seperti negara lainnya (Makdori 2019).

Pengetahuan tentang menyelamatkan diri sejak dini di Provinsi Riau masih sangat minim diajarkan meskipun fasilitas-fasilitas untuk penanggulangan seperti ketika kebakaran terjadi difasilitasi. Akibatnya, anak-anak hingga dewasanya kurang memiliki kesadaran yang tinggi akan pentingnya kemampuan untuk menyelamatkan diri. Oleh karena itu, diperlukan fasilitas belajar dan pelatihan dimana masyarakat Riau mendapat pendidikan bencana yang sudah disesuaikan dengan karakteristik dan diperbarui sesuai dengan kejadian-kejadian terbaru.

Dengan bencana yang kerap terjadi, Provinsi Riau sewajarnya memiliki pusat pelatihan dalam menghadapi bencana dan bukan hanya sekedar kantor, oleh karena itu upaya yang dilakukan adalah dengan merancang pusat mitigasi dan disaster management di Pekanbaru, Riau.

Riau Mitigation and Disaster Management Center dirancang sebagai tempat bagi masyarakat untuk belajar dan berlatih tentang mitigasi dan manajemen bencana. Mitigasi difokuskan pada bencana yang umum terjadi di Riau seperi banjir, kebakaran, dan gempa. Selain itu, fasilitas akan memiliki ruang simulasi indoor dan lapangan simulasi, museum, ruang audio-visual, serta tempat evakuasi akhir bagi korban ketika bencana sesungguhnya datang.

Berdasarkan permasalahan yang telah disebutkan, maka fasilitas Riau Mitigation and Disaster Management Center tepat jika dirancang dengan pendekatan yang menghargai alam, mengambil bentukan-bentukan dari alam, menciptakan suasana yang dekat dengan alam dengan cara menghadirkan ruang yang dirancang menggunakan pencahayaan alami, serta sesuai dengan kondisi geografis, budaya, dan ekologi setempat. Maka dari itu, pendekatan rancangan yang sesuai untuk bangunan ini adalah pendekatan desain biofilik.

Pendekatan desain biofilik dapat mendukung fungsi bangunan dalam segi bentukan dan yang dapat memberikan dampak positif pada fisik dan psikologi manusia termasuk ketika bencana terjadi (Joye 2007). Penggunaan pendekatan prinsip desain arsitektur biofilik menjadikan fasilitas harus dekat dengan alam dengan menggunakan elemen-elemen tersebut. Elemen- elemen dari alam dapat meningkatkan produktivitas dan kesehatan fisik serta mental pengguna, serta memberikan rasa aman dan nyaman kepada pengungsi yang akan menjadikan fasilitas ini sebagai tempat evakuasi akhir.

Riau Mitigation and Disaster Management Center diharapkan dapat menjadi fasilitas guna meningkatkan kesadaran masyarakat bahwa bencana dapat datang kapan saja dan dimana saja serta tentang pentingnya kemampuan menaggulangi bencana; serta meningkatkan pengetahuan dan kemampuan masyarakat tentang penanggulangan bencana.

\section{Metode penelitian}

\section{Paradigma}

Riau Mitigation and Disaster Management Center merupakan tempat dimana masyarakat terutama anak-anak memperoleh edukasi tentang kebencanaan, pelatihan simulasi dalam menghadapi bencana dan bagaimana mempersiapkan diri ketika bencana terjadi. Kegiatan simulasi dilakukan sebagai edukasi dilakukan di luar ruangan dan rekreasi serta belajar di dalam ruangan. Hal ini membuat fasilitas-fasilias ini harus dirancang ramah keluarga dan nyaman untuk digunakan sehingga pengguna dapat berlama-lama berada di lingkungan ini. Selain itu, bangunan ini dilengkapi dengan tempat evakuasi akhir bagi korban ketika bencana sesungguhnya terjadi. Kegiatan evakuasi yang mengatur kembalinya kesehatan fisik dan mental korban bencana juga membutuhkan fasilitas yang dapat memberikan rasa nyaman dan aman kepada korban.

Kenyamanan akan merangsang kreativitas dan produktivitas pengguna dan membuat pengguna aktif, juga menciptakan rasa aman serta kesehatan fisik dan mental caranya dengan menghadirkan bangunan yang dekat dengan alam dan menghargai alam (Pudianti and Vitasurya 2019). Maka dari itu, desain biofilik akan diterapkan kepada bangunan dengan cara menerapkan keenam prinsip utama desain biofilik yang mana menjadi standar bagi bangunan yang menggunakan pendekatan tersebut. Tiap prinsip biofilik memiliki atribut-atributnya tersendiri. Total atribut dari semua prinsip adalah 70 atribut dan tidak semua atribut harus diterapkan pada bangunan. Oleh karena itu, pada perancangan Riau Mitigation and Disaster Management akan 
digunakan beberapa atribut dari tiap prinsip saja, yaitu:

1. Fitur lingkungan: penggunaan material alami, bukaan, view dan vistas;

2. Bentuk-bentuk alam: menggunakan motif botanis, menggunakan bentuk lengkung;

3. Pola dan proses alam: ruang-ruang yang diikat, ruang-ruang transisi;

4. Cahaya dan ruang: penerapan cahaya alami, cahaya yang disaring dan difusikan, cahaya dan bayangan, adanya cahaya yang terpantul, keluasan ruang, keselarasan ruang, ruang bagian dalam-luar;

5. Hubungan berbasis ruang: hubungan geografis antara bangunan dan tempat, fitur lansekap menentukan bangunan;

6. Hubungan evolusi manusia-alam: refuge, menciptakan rasa ingin tahu, penguasaan dan pengendalian, atraksi dan keindahan, eksplorasi dan penemuan.

\section{Strategi perancangan}

Strategi perancangan Mitigation and Disaster Management Center adalah: Tahap awal: survey, analisa site, analisa kebutuhan ruang, zoning, membuat program ruang, membuat pola hubungan antar ruang; Tahap kedua: konsep, tatanan massa, tatanan ruang luar, bentukan massa, sistem struktur, tatanan ruang dalam, utilitas, fasad bangunan, interior, detail lansekap; Tahap akhir: perancangan dan hasil desain (Lihat gambar 1).

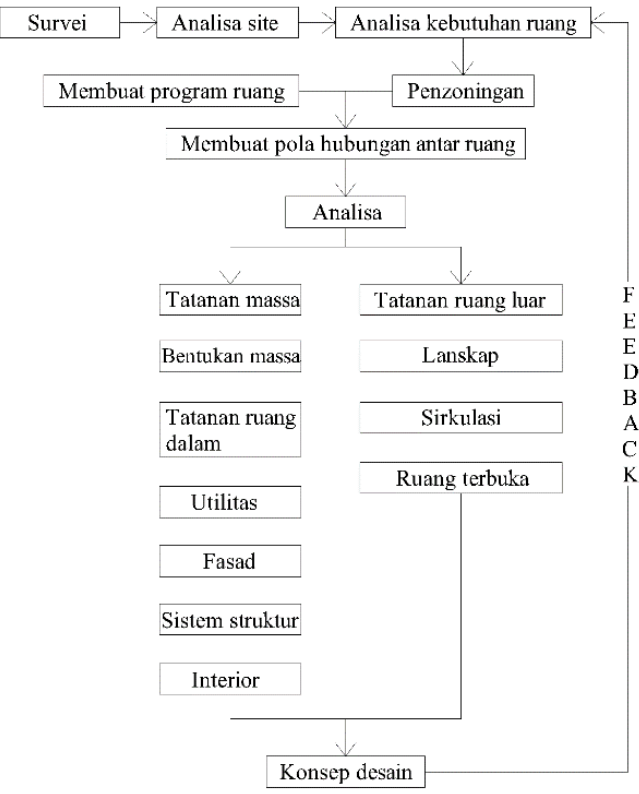

Gambar 1. Bagan strategi perancangan
Metode pengumpulan data

Metode pengumpulan data adalah dengan survey lapangan dan mencari sumber literatur dari buku, jurnal, dan media tentang prinsip desain arsitektur biofilik dan pusat mitigasi dan penanggulangan bencana.

\section{Temuan dan pembahasan}

Disaster management atau penanggulangan bencana adalah serangkaian upaya yang meliputi penetapan kebijakan pembangunan yang berisiko timbulnya bencana, kegiatan pencegahan bencana, tanggap darurat, dan rehabilitasi (Presiden Republik Indonesia 2007).

Manajemen bencana juga dapat diartikan sebagai upaya untuk merencanakan, mengorganisasikan, mengawasi, melaksanakan segala sumberdaya jika terjadi bencana pada suatu daerah (Mareta 2014).

Pengertian mitigasi (mitigation) adalah upaya untuk mengurangi risiko bencana, baik melalui pembangunan fisik maupun penyadaran dan peningkatan kemampuan menghadapi bencana (Presiden Republik Indonesia 2008).

Berdasarkan definisi-definisi di atas, dapat diambil kesimpulan bahwa pusat mitigasi dan manajemen bencana merupakan tempat diselenggarakannya kegiatan untuk penyadaran dan peningkatan kemampuan mempersiapkan diri menghadapi bencana.

\section{Desain biofilik}

Desain biofilik pertama kali dikenalkan oleh Steven Kellert (Gullikson 2010). Pernyataan Kellert yang dikutip oleh Sumartoni, 2015 menyatakan tujuan dari desain biofilik ini adalah bagaimana memasukkan pemahaman 'biofilia' ke dalam lingkungan binaan sehingga terjadi interaksi antar alam dan manusia dalam bangunan yang menyehatkan (Sumartono 2017). Desain biofilik memiliki dua dimensi utama yaitu, dimensi organtik atau naturalistik dan dimensi berbasis tempat atau vernakular (Sumartono 2015).

Dimensi organik atau naturalistik diartikan sebagai bentuk-bentuk yang ada di lingkungan binaan yang secara langsung, tidak langsung, atau simbolis mencerminkan keterikatan manusia dengan alam (Kellert, Heerwagen, and Mador 2013). Dimensi organik dapat berupa kontak langsung dengan alam, misalnya penggunaan 
jendela besar yang membuat pengguna berhubungan langsung dengan alam seperti tanaman, hewan, dan ekosistem (Widodo 2019; Subroto 2019). Dimensi organik tidak langsung bisa berupa penggunaan air mancur, akuarium, atau tanaman pot. Secara simbolis, dimensi organik dapat berupa pengalaman tanpa kontak langsung dengan alam, melainkan representasinya seperti dari foto, video, dan lainlain.

Dimensi berbasis tempat atau vernakular diartikan sebagai bangunan atau lanskap yang menghubungkan budaya dan ekologi lokal atau suatu area geografis (Sumartono 2017). Dimensi ini memberikan sebuah 'rasa' atau spirit pada suatu ruang dan agar menghindari 'ketidakhadiran tempat' (placelessness).

Kedua dimensi memiliki enam unsur utama yang dapat digunakan dalam perancangan arsitektur biofilik (Kellert, Heerwagen, and Mador 2013). Keenam unsur tersebut ini adalah standar perancangan Biofilik, yaitu: (1) Environtmental features (fitur lingkungan); (2) Natural shapes and forms (bentuk-bentuk alami); (3) Natural patterns and processes (pola pola dan proses alami); (4) Light and space (cahaya dan ruang); (5) Place-based relationships (hubungan berbasis ruang); (6) Evolved human-nature relationships (hubungan evolusi manusia-alam) (Kellerts 1993).

\section{Lokasi perancangan}

Lokasi: Jln. Datuk Setia Maharaja, Kec. Bukit Raya, Kota Pekanbaru; Letak geografis: N 773333.38 E 53168.99; Luas: 2,6 Ha (Lihat gambar 2).

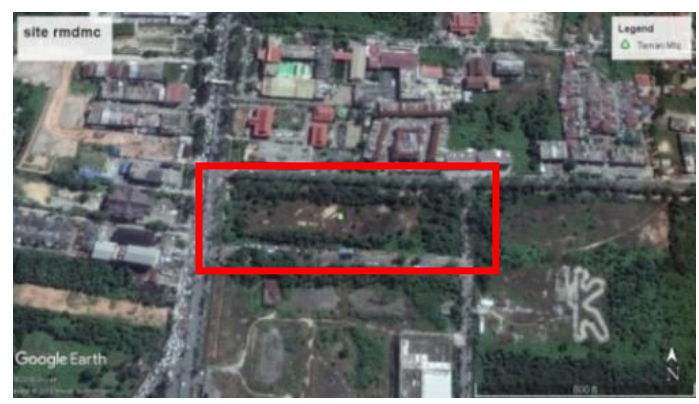

Gambar 2. Lokasi perancangan

Lokasi perancangan berbatasan dengan: (a) Sebelah Utara berbatasan dengan gedung Guru dan perkantoran Grand Sudirman; (b) Sebelah Selatan berbatasan dengan MTQ; (c) Sebelah Timur berbatasan dengan Jalan Datuk Wan Abdul
Jamal; dan (d) Sebelah Barat berbatasan dengan Jalan Jendral Sudirman.

Lokasi ini dipilih setelah melalui beberapa pertimbangan seperti luas site yang cukup, lokasi yang strategis, akses yang dekat dari Jendral Sudirman, dan jalan yang lebar sehingga terhindar dari kemacetan (Lihat gambar 3).
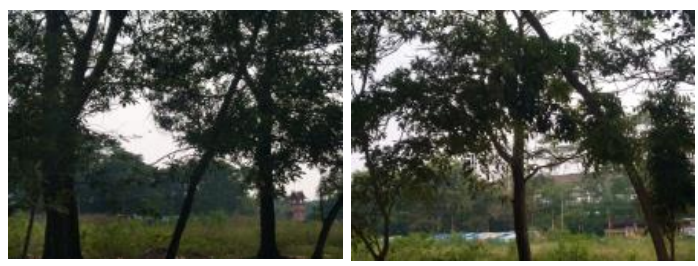

View dari dalam site
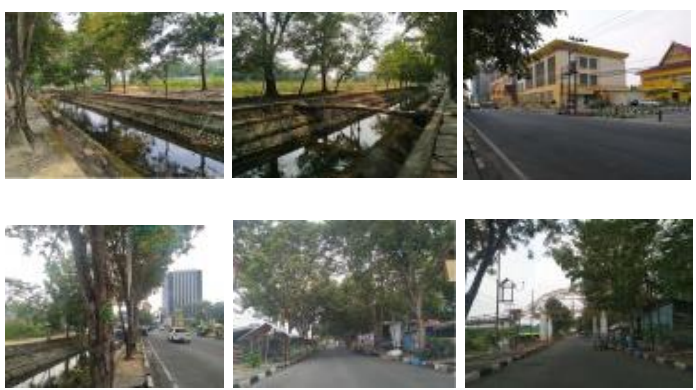

View ke luar site

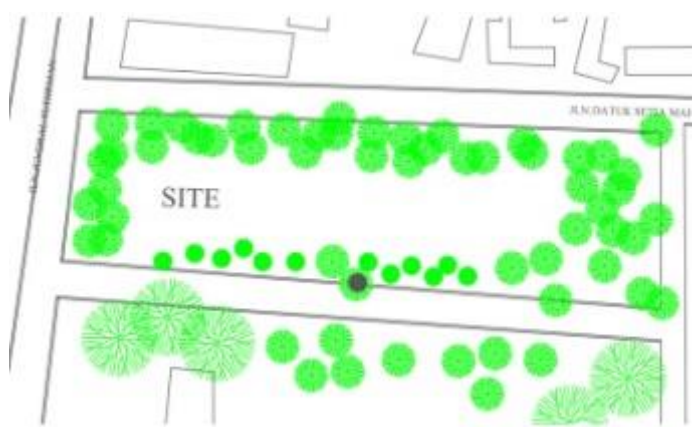

Gambar 3. View dari dalam site dan ke luar site

Patokan yang diambil merupakan Koefisien Dasar Bangunan (KDB), Koefisien Lantai Bangunan (KLB), Ketinggian Bangunan, dan Garis Sempadan Pagar Bangunan (Lihat tabel 1). Pada konteks Riau Mitigation and Disaster Management Center, aturan yang ditetapkan adalah berdasarkan Peraturan Daerah Kota Pekanbaru Nomor 14 Tahun 2000 tentang Izin Banguan dalam Daerah Kota Pekanbaru (Lihat gambar 4). 


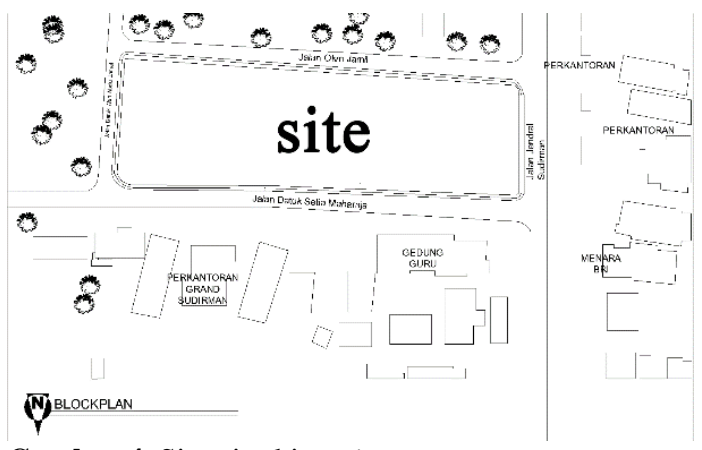

Gambar 4. Situati sekitar site

Tabel 1. KDB, KLB, dan ketinggian lantai bangunan

\begin{tabular}{|c|c|c|c|}
\hline No & Jenis bangunan & KDB & $\begin{array}{l}\text { Jumlah lantai } \\
\text { maksimal }\end{array}$ \\
\hline 1 & Perumahan & & \multirow{4}{*}{ Kurang 3 lantai } \\
\hline & $\begin{array}{ll}\text { a. } & \text { Kavling } 300 \mathrm{M} 2 \mathrm{ke} \\
\text { atas }\end{array}$ & 0,50 & \\
\hline & $\begin{array}{ll}\text { b. Kavling } & 150-300 \\
\text { M2 }\end{array}$ & 0,60 & \\
\hline & $\begin{array}{l}\text { c. Kavling } 150 \text { M2 ke } \\
\text { bawah }\end{array}$ & 0,75 & \\
\hline 2 & $\begin{array}{l}\text { Perkantoran di pusat } \\
\text { kota }\end{array}$ & 0,75 & 8 lantai \\
\hline 3 & $\begin{array}{l}\text { Perkantoran di sub } \\
\text { pusat kota }\end{array}$ & 0,35 & 4 lantai \\
\hline 4 & $\begin{array}{l}\text { Perdagangan dan jasa } \\
\text { di pusat kota }\end{array}$ & 0,70 & 8 lantai \\
\hline 5 & $\begin{array}{l}\text { Perdagangan dan jasa } \\
\text { di sub pusat kota }\end{array}$ & 0,70 & 4 lantai \\
\hline 6 & Industri dan gedung & 0,45 & 2 lantai \\
\hline 7 & Pelayanan sosial & 0,45 & 4 lantai \\
\hline
\end{tabular}

Sumber: (Walikota Pekanbaru 2000)

Kebutuhan ruang

Adapun fasilitas yang ada di bangunan dibagi menjadi fasilitas publik, pengelola, dan servis (Lihat tabel 2).

Tabel 2. Kebutuhan ruang publik

\begin{tabular}{ll} 
Nama Ruang & Luas \\
\hline Ruang publik & $2424,37 \mathrm{~m}^{2}$ \\
\hline Ruang pengelola & $357,24 \mathrm{~m}^{2}$ \\
\hline Ruang servis & $302,9 \mathrm{~m}^{2}$ \\
\hline Total & 3084,51 \\
\hline
\end{tabular}

Penzoningan

Penzoningan pada Riau Mitigation and Disaster Management Center dibagi menjadi zona parkir, zona bangunan, dan zona pelatihan (Lihat gambar 5). Zoning pada Riau Mitigation and Disaster Management Center memperhatikan keadaan sekitar tapak dan pergerakan kendaraan yang keluar masuk, kegiatan simulasi, dan pengguna. Zona parkir diletakkan di bagian Barat tapak agar mempermudah kendaraan yang masuk dan keluar, selain itu bagian ini juga dekat dengan jalan raya yang tingkat kebisingannya tinggi. Selain itu, penzoningan juga didasari oleh penerapan atribut prinsip biofilik placed-based relationship yaitu hubungan bangunan dengan kondisi geografis.

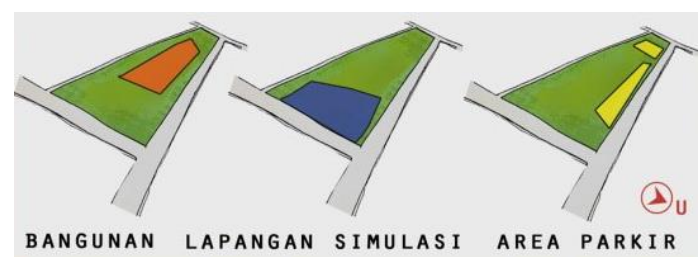

Gambar 4. Analisis penzoningan

\section{Konsep}

Konsep dasar

Konsep dasar desain Riau Mitigation and Disaster Management Center ini adalah kupukupu, merupakan lambang dari kehidupan dan dihubungkan dengan jiwa manusia. Pada beberapa kepercayaan kupu-kupu dilambangkan sebagai penghidupan kembali dan banyak kebudayaan dilambangkan sebagai daya tahan, perubahan, dan harapan. Selain itu, kupu-kupu dapat mendeteksi perubahan cuaca. Hal ini setara dengan dasar dari mitigasi dan manajemen bencana yang memberikan masyarakat kemampuan, pengetahuan, dana harapan untuk bertahan hidup (Lihat gambar 6).

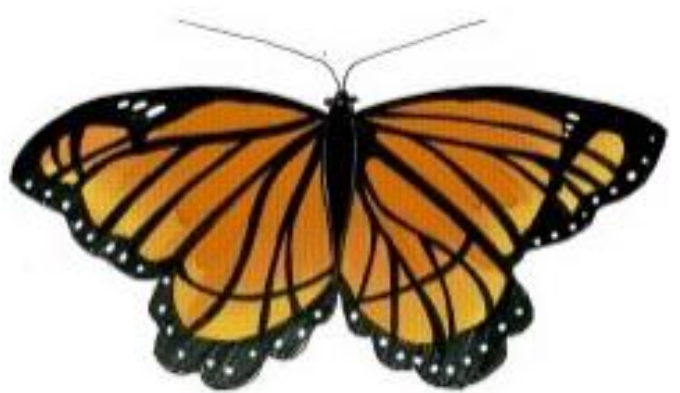

Gambar 5. Kupu-kupu sebagai konsep dasar

Bentukan diambil dari kupu-kupu yang sedang membentang sayapnya karena saat itulah kupu-kupu sedang aktif, mewakilkan fungsi fasilitas dimana kegiatannya cukup aktif. Bentangan kupu-kupu diambil sebagai luas membran untuk bentukan atap bangunan (Lihat gambar 7). 


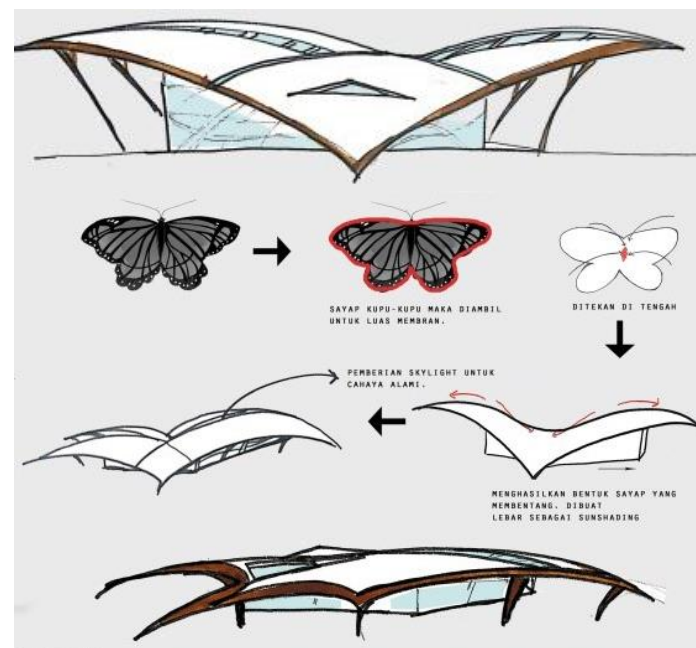

Gambar 7. Transformasi bentukan

Konsep kupu-kupu yang diterapkan pada tapak mengambil pola-pola rangka dari sayap untuk membentuk pola tapak. Dari pola ini kemudian disesuaikan dengan penzoningan parkir, bangunan, dan lapangan simulasi (Lihat gambar 8).

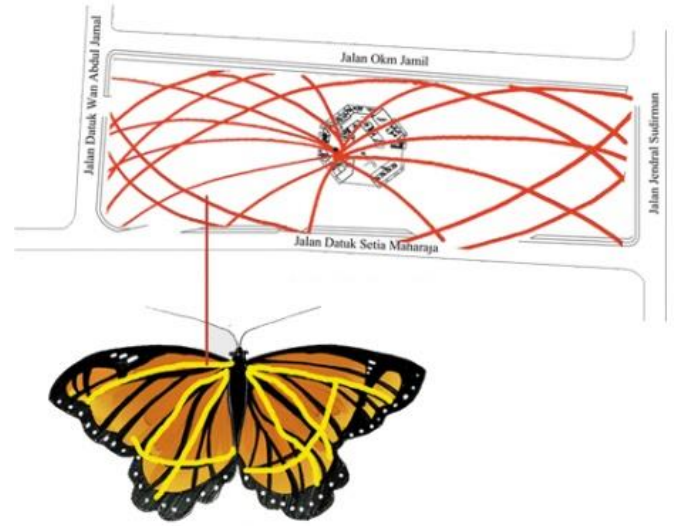

Gambar 6. Pola tapak

Zona simulasi diletakkan di bagian Timur tapak yang mana mendapatkan sinar matahari yang baik (Lihat gambar 9).

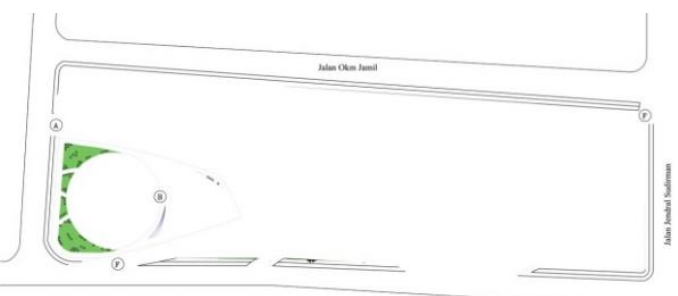

Gambar 7. Zona simulasi
Zona parkir terdiri dari parkir kendaraan roda dua, kendaraan roda empat, dan bus. Zona ini diletakkan di area sebelah Barat dan belakang sehingga, tidak akan mengganggu pergerakan pengguna lapangan simulasi (Lihat gambar 10).

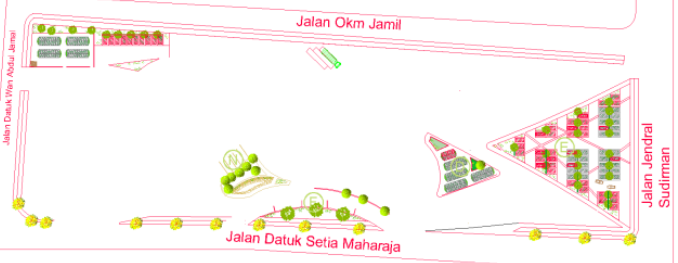

Gambar 8. Zona parkir

Zona bangunan berada di tengah, diletakkan agak jauh dari utara dan barat bangunan yang mana jalan raya dan tingkat kebisingannya tinggi (Lihat gambar 11).

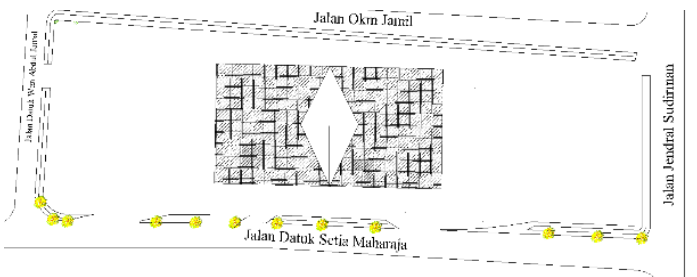

Gambar 9. Zona bangunan

\section{Penerapan desain}

Penerapan desain pada Riau Mitigation and Disaster Management Center adalah prinsipprinsip desain arsitektur biofilik oleh Stephen Kellert. Inti dari prinsip-prinsip biofilik adalah bagaimana cara membuat pengguna tetap merasa dekat dengan alam meskipun berada di lingkungan binaan. Prinsip-prinsip tersebut memiliki atributnya masing-masing dan beberapa dari atribut tersebut dipilih kemudian diterapkan pada fasilitas ini.

Pada interior bangunan, penggunaan atributatribut dari prinsip-prinsip biofilik oleh Stephen Kellert adalah sebagai berikut:

\section{Environmental features}

Pada bangunan, penerapan fitur lingkungan dilakukan dengan penggunaan material kayu dan warna-warna yang natural pada beberapa elemen bangunan seperti sunshading. Pada lanskap diberikan elemen air pada bagian di depan bangunan. Interior bangunan seperti lobby diberikan elemen-elemen natural seperti bebatuan. Pemberian bukaan-bukaan agar cahaya matahari masuk dan sirkulasi udara dapat berjalan dengan baik. Selain itu, vegetasi juga diberikan di 
luar dan dalam bangunan. Penerapan view dan vistas dengan menyediakan view alam kepada pengguna di dalam ruangan merupakan bagian dari penerapan dari prinsip ini (Lihat gambar 12).

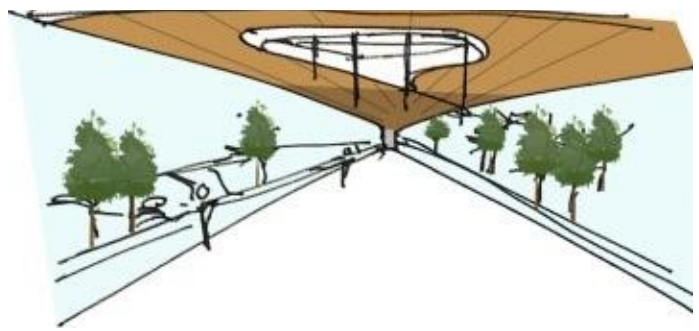

Gambar 10. Analisis penerapan atribut dari prinsip environmental features

\section{Natural shapes and form}

Prinsip ini lebih diterapkan pada bentukan bangunan dengan mengambil bentukan-bentukan alam dan digabungkan dengan atribut arch kemudian mentransformasikannya berdasarkan konsep yang telah ditentukan. Dengan fungsi bangunan sebagai wadah edukasi, maka atribut ini akan cocok pada bangunan ini (Lihat gambar 13).

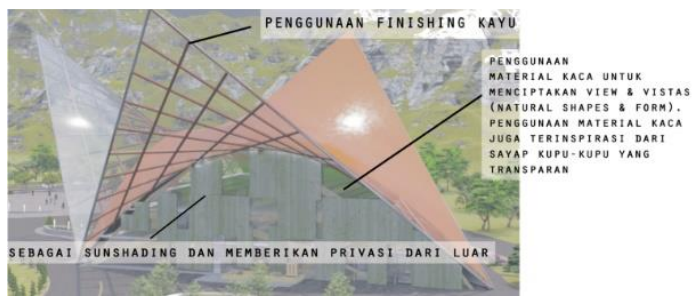

Gambar 11. Analisis penerapan atribut pada prinsip natural shapes and forms

\section{Natural patterns and process}

Penerapan prinsip ini pada bangunan dengan menggunakan atribut ruang-ruang transisi dan ruang yang diikat. Atribut ruang-ruang transisi diterapkan dengan cara memberikan area transisi antara bangunan dan lingkungan baik dengan penggunaan jendela dan pintu, sementara ruangruang yang diikat diterapkan dengan cara memberikan batasan yang jelas antara ruang publik, privat, semi-publik, dan servis dengan cara penggunaan dinding dan membatasi antara gedung utama dan pengelola dengan lobby (Lihat gambar 14).

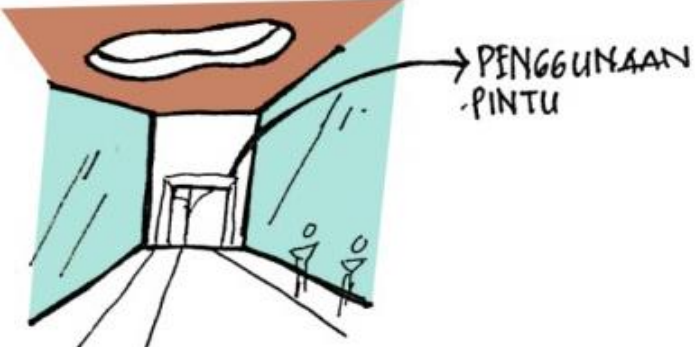

Gambar 14. Analisis penerapan atribut dari prinsip natural patterns and process

\section{Light and spaces}

Penerapan prinsip ini dengan pemberian kaca agar cahaya alami dan masuk ke dalam ruangan baik dengan menggunakan atribut cahaya yang disaring dan difusikan. Dengan penggunaan kaca, maka atribut-atribut seperti: cahaya alami, cahaya dan bayangan, memberikan keleluasaan ruang, serta ruang sebagai bentuk dapat dipenuhi. Sementara penggunaan lampu seperti spotlight dapat memenuhi penerapan atribut adanya cahaya terpantul (Lihat gambar 15).

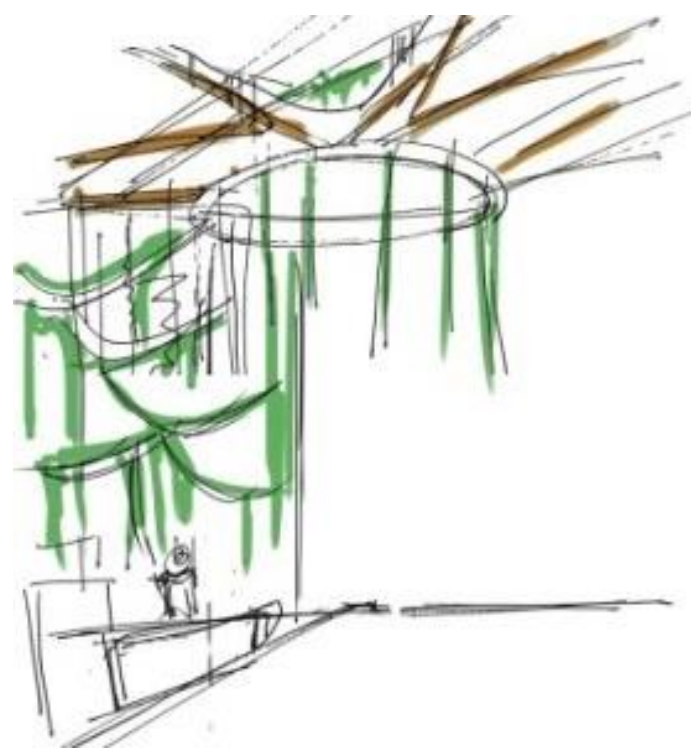

Gambar 12. Analisis penerapan atribut dari prinsip light and spaces

Atribut memberikan keleluasaan ruang diterapkan dengan cara memberikan ruangan yang memang dirancang lebih luas dari ruangan lain dan pemberian material kaca pada ruangan tersebut. Atribut ruang sebagai bentuk diterapkan dengan cara menerapkan batas antara ruang sehingga menstimulasi rasa ingin tahu pengguna. Atribut ruang bagian dalam-luar diterapkan dengan pemberian atrium dan taman indoor. 
Sementara atribut keselarasan ruang akan diterapkan dengan mengkombinasikan bangunan, cahaya, dan skala yang memang harus dilakukan.

\section{Place based relationship}

Perancangan bangunan dan lanskap harus memikirkan kondisi geografis dan budaya setempat sehingga nantinya dapat menghadirkan spirit tempat untuk menghindari kesan ketiadaan pada bangunan dengan cara merancang lanskap dan bangunan yang familiar bagi pengguna, perletakkan ruang servis yang terpisah dengan ruang publik, dan sebagainya. Penggunaan material lokal seperti kayu juga digunakan untuk memberikan rasa familiar tersebut. Sementara, untuk penerapan fitur-fitur lanskap yang mendefinisikan bangunan dilakukan dengan cara menyesuaikan rancangan lanskap dengan konsep bangunan sehingga kedua elemen ini dapat saling menyatu dan memberikan cerita yang sama (Lihat gambar 16).

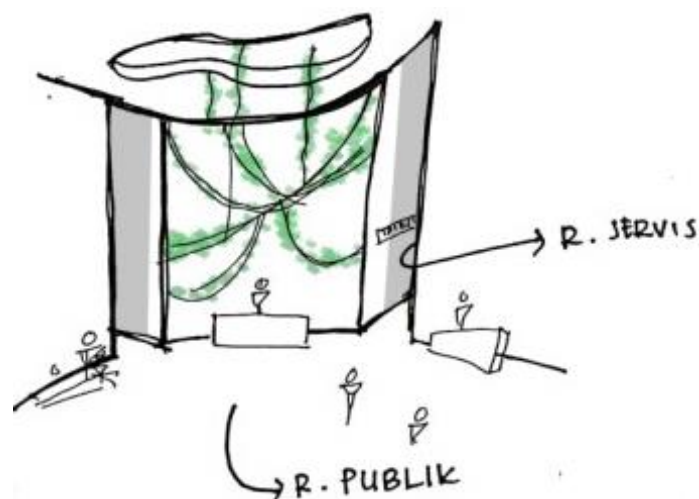

Gambar 13. Analisis penerapan atribut dari prinsip placed based relationship

\section{Evolved human-nature relationship}

Riau Mitigation and Disaster Management Center menerapkan atribut refuge dengan menyediakan partisi pada ruang-ruang kantor dan memberikan vegetasi untuk rasa aman di ruang evakuasi akhir. Atribut rasa ingin tahu dan pemenuhannya dilakukan dengan memberikan koridor-koridor yang akan mengarahkan pengguna ke bagian ruangan yang lain serta untuk menerapkan atribut eksplorasi dan penemuan. Atribut penguasaan dan pengendalian diterapkan dengan cara merancang bangunan yang tetap menghargai alam di sekitarnya untuk mengendalikan ketidakharmonisan yang diakibatkan konstruksi bangunan dengan alam serta dengan menerapkan atribut dari atraksi dan keindahan yang menekankan pada penggunaan unsur alam (Lihat gambar 17).

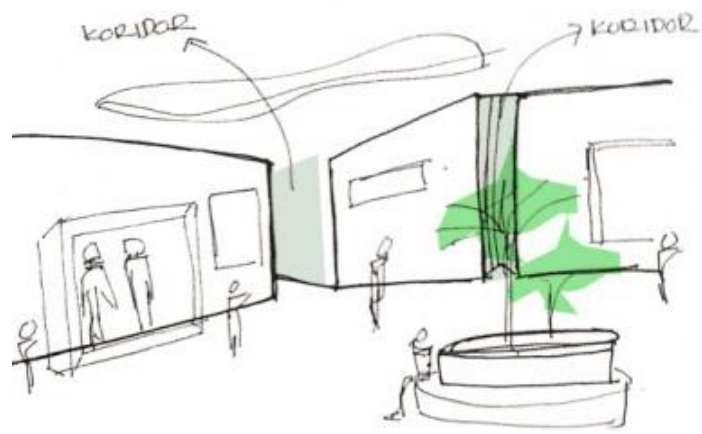

Gambar 14. Analisis penerapan atribut dari prinsip evolved human-nature relation

\section{Sistem sanitasi dan plumbing}

Sistem sanitasi dan plumbing yang digunakan pada dua yaitu distribusi air bersih dan distribusi air kotor.

1. Distribusi Air Bersih

Distribusi air bersih menggunakan sistem down feed dan rain haervesting (Lihat gambar 18). Sistem down feed adalah sistem dimana air dari tangki bawah ditampung kemudian didistribusikan ke tangki di atas bangunan dan disebarkan ke seluruh ruangan (Lihat gambar 19). Sistem ini memiliki keuntungan yaitu: (a) Efisien; (b) Perubahan tekanan pada alat plumbing ketika air digunakan tidak berpengaruh apapun; (c) Sistem pemompaan air ke atas bekerja secara otomatis dan sederhana; (d) Perawatan tangki sederhana.

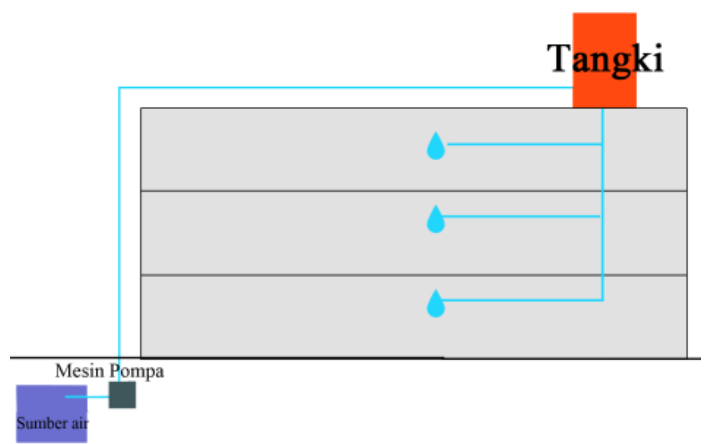

Gambar 15. Skema sistem down feed distribution 


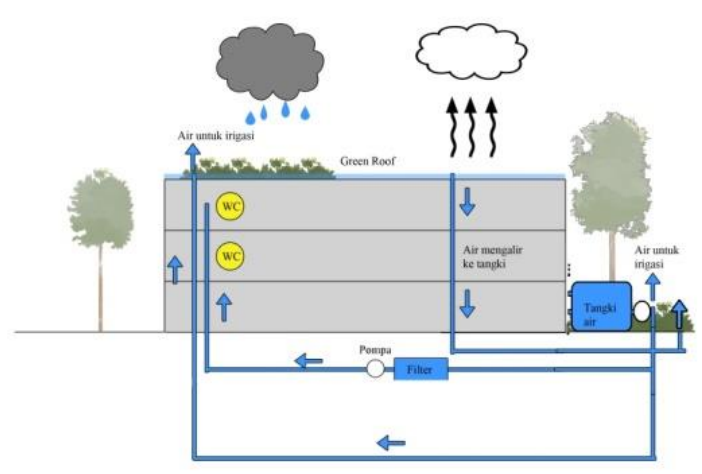

Gambar 19. Skematik rainwater harvesting pada green roof

2. Distribusi air kotor

Distribusi air kotor dibagi menjadi dua yaitu air kotor dan air kotoran. Air kotor berasal dari buangan air yang terpakai dari wastafel, dapur, janitor, dan sebagainya. Sedangkan air kotoran berasal pembuangan kloset (Lihat gambar 20).

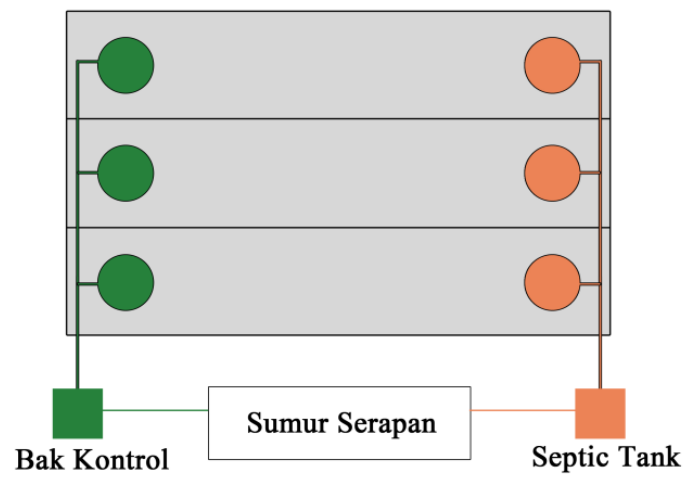

Gambar 16. Skematik air kotor

\section{Kesimpulan}

Riau Mitigation and Disaster Management Center merupakan bangunan yang menggabungkan fungsi edukasi, rekreasi, simulasi, kantor pengelola, dan tempat evakuasi akhir yang menggunakan pendekatan desain biofilik di Pekanbaru, Riau. Kupu-kupu yang menjadi lambang dari kehidupan dan harapan hidup adalah konsep yang diterapkan pada bangunan. Penerapan arsitektur biofilik cocok apabila diterapkan pada fasilitas Riau Mitigation and Disaster Management Center karena kedekatan pengguna dengan alam akan meningkatkan produktivitas dan diharapkan memberikan rasa aman ketika evakuasi. Selain itu, fasilitas dilengkapi dengan green roof untuk rainwater harvesting untuk menanggapi kondisi Pekanbaru, Riau yang cenderung kekeringan ketika musim kemarau dan dengan pemberian vegetasi juga akan memberikan penghawaan alami di Pekanbaru yang sinar mataharinya cukup tinggi.

\section{Referensi}

Gullikson, Christina L. 2010. 'Human Connection to Nature Within the Build Environment: An Exploration of Office Employee Perception of Nature Connectedness'. Florida State University. https://diginole.lib.fsu.edu/islandora/object/fs u\%3A182148.

Joye, Yannick. 2007. 'Architectural Lessons from Environmental Psychology: The Case of Biophilic Architecture'. Review of General Psychology $11 \quad$ (4): $\quad 305-28$. https://doi.org/10.1037/1089-2680.11.4.305.

Juandi, Andi. 2015. 'Penanganan Bencana Di Indonesia Belum Optimal'. Elshinta.Com: News and Information Online, 6 October 2015.

https:/www.elshinta.com/news/28456/2015/ 10/06/penanganan-bencana-di-indonesiabelum-optimal.

Kellert, Stephen R., Judith Heerwagen, and Martin Mador. 2013. Biophilic Design: The Theory, Science and Practice of Bringing Buildings to Life. New Jersey: Wiley.

Kellerts, S. R. 1993. The Biophilia Hypothesis. Edited by E. O. Wilson. Washington: Island Press.

Kusmajaya, Sumardani, Supriyati Supriyati, Agung Adiputra, and M. Galih Permadi. 2019. 'Pemetaan Bahaya Dan Kerentanan Bencana Kebakaran Hutan Dan Lahan Di Provinsi Riau'. Jurnal Geografi, Edukasi Dan Lingkungan (JGEL) $3 \quad$ (1): 55. https://doi.org/10.29405/jgel.v3i1.2993.

Madona, Era, and Muhammad Irmansyah. 2013. 'Aplikasi Metode Nearest Neighbor Pada Penentuan Jalur Evakuasi Terpendek Untuk Daerah Rawan Gempa Dan Tsunami'. Elektro: Jurnal Ilimah 5 (2): 39-46. https://doi.org/https://doi.org/10.30630/eji.5.2 .52 .

Makdori, Yopi. 2019. 'BNPB: Mitigasi Bencana Masyarakat Indonesia Masih Di Bawah 
Standar'. Liputan6, 18 February 2019. https://www.liputan6.com/news/read/390632 5/bnpb-mitigasi-bencana-masyarakatindonesia-masih-di-bawah-standar.

Mareta, Nandian. 2014. 'Pengetahuan Dan Manajemen Bencana'. Jakarta. https://www.researchgate.net/publication/328 230942_PENGETAHUAN_DAN_MANAJE MEN_BENCANA.

Pemerintah Pusat. 2015. Instruksi Presiden (INPRES) Tentang Peningkatan Pengendalian Kebakaran Hutan Dan Lahan. Indonesia: LL SETKAB https://peraturan.bpk.go.id/Home/Details/773 79/inpres-no-11-tahun-2015.

Presiden Republik Indonesia. 2007. UndangUndang Republik Indonesia Nomor 24 Tahun 2007 Tentang Penanggulangan Bencana. Indonesia.

https://bnpb.go.id/ppid/file/UU_24_2007.pdf. . 2008. Peraturan Pemerintah Republik Indonesia Nomor 21 Tahun 2008 Tentang Penyelenggaraan Penanggulangan Bencana. Indonesia.

https://bnpb.go.id/ppid/file/PP_No._21_Th_2 008.pdf.

Pudianti, Anna, and Vincentia Reni Vitasurya. 2019. 'Pendekatan Antropologi Sebagai Penyeimbang Model Perhitungan Jejak Ekologis Di Desa Wisata'. ARTEKS : Jurnal Teknik Arsitektur 4 (1): 33-44. https://doi.org/10.30822/arteks.v4i1.77.

Subroto, Tarcicius Yoyok Wahyu. 2019. 'Koeksistensi Alam Dan Budaya Dalam Arsitektur'. ARTEKS: Jurnal Teknik
Arsitektur 3 https://doi.org/10.30822/arteks.v3i2.60. Sudradjat, Iwan. 2020. 'Teori Dalam Penelitian Arsitektur'. ARTEKS: Jurnal Teknik Arsitektur $\quad 5 \quad$ (1): $\quad$ i-vi. https://doi.org/10.30822/arteks.v5i1.378.

Sumartono. 2015. 'Prinsip-Prinsip Desain Biofilik'. PRODUCTUM Jurnal Desain Produk (Pengetahuan Dan Perancangan Produk) 1 (1): 15-21.

Sumartono, Sumartono. 2017. 'Prinsip-Prinsip Desain Biofilik'. PRODUCTUM Jurnal Desain Produk (Pengetahuan Dan Perancangan Produk) 1 (1): 15. https://doi.org/10.24821/productum.v1i1.151 5.

Walikota Pekanbaru. 2000. Peraturan Daerah Kota Pekanbaru Nomor 14 Tahun 2000 Tentang Izin Bangunan Dalam Daerah Kota Pekanbaru. Indonesia. https://pekanbaru.go.id/d/perda/04092009/20 00-1491.pdf.

Wibowo, Agus, Indra Surbakti, and Ridwan Yunus. 2013. 'Indonesia Disaster Database'. Sendai, Japan. https://www.unescap.org/sites/default/files/S 2-3_Indonesia.pdf.

Widodo, Johannes. 2019. 'Human, Nature, And Architecture'. ARTEKS: Jurnal Teknik Arsitektur 3 (2): 145-48. https://doi.org/10.30822/arteks.v3i2.65.

Yulaelawati, Ella. 2008. Mencerdasi Bencana. Jakarta: Grasindo. 